\title{
The Role of Surgery for Pancreatic Neuroendocrine Tumors
}

\author{
IOANNIS A. ZIOGAS ${ }^{1}$, ROBIN SCHMITZ ${ }^{2}$, DIMITRIOS MORIS ${ }^{2}$ and CORY J. VATSAAS ${ }^{2}$ \\ ${ }^{1}$ Department of Surgery, Division of Hepatobiliary Surgery and Liver Transplantation, \\ Vanderbilt University Medical Center, Nashville, TN, U.S.A.; \\ ${ }^{2}$ Department of Surgery, Duke University Medical Center, Durham, NC, U.S.A.
}

\begin{abstract}
Pancreatic neuroendocrine tumors (PNETs) arise from endocrine pancreatic cells and comprise 3-5\% of pancreatic cancers. Surgical resection is the only potentially curative option for PNETs. Surgical candidates should be carefully selected according to tumor functionality, size, location, grade, and stage. Current guidelines state that patients with neuroendocrine carcinoma may not be surgical candidates due to aggressive tumor behavior and poor prognosis, while in cases of PNET with unresectable metastatic disease, resection may be of benefit in certain patients. The current guidelines recommend resection of any size of functional PNETs and of non-functional PNETs $>2 \mathrm{~cm}$. Watchful waiting is recommended for patients with non-functional PNETs $<1 \mathrm{~cm}$. Further evidence is needed to determine whether surgery for nonfunctional PNETs of 1-2 cm would be of benefit or if surgery should be individualized. This review aimed to discuss the current literature on the management of PNETs and highlight the utility of surgery in treatment.
\end{abstract}

Pancreatic neuroendocrine tumors (PNETs) arise from hormone-producing cells of the pancreas (1) and account for $3-5 \%$ of all pancreatic malignancies (2). Functional PNETs can secrete a variety of peptide hormones, however, the majority of PNETs are non-functional $(3,4)$. Due to the increasing use and improved accuracy of cross-sectional imaging (5), PNETs have an increasing incidence $(6,7)$. This

This article is freely accessible online.

Correspondence to: Dimitrios Moris (ORCID 0000-0002-52760699), MD, MSc, PhD, Department of Surgery, Duke University Medical Center, 2301 Erwin Road, Durham, NC 27710, USA. E-mail: dimitrios.moris@duke.edu

Key Words: Pancreatic neuroendocrine tumor, PNET, neuroendocrine carcinoma, surgery, resection, review. leads to more frequent consultations with general surgeons and surgical oncologists. Despite the increasing availability of options for the management of PNETs, including somatostatin analogs, temozolomide-based chemotherapy, targeted therapies (e.g., sunitinib, everolimus), peptide receptor radionuclide therapy (PRRT), and immunotherapy (8-10), surgery is the only option that can be potentially curative. Therefore, determining timing of surgical management for these patients is crucial. There are several factors that determine the applicability of surgical treatment for PNETs, which include tumor staging, differentiation, size, functionality, and location. The aim of this review is to summarize these considerations and discuss when surgery is indicated for PNETs.

\section{Diagnostic Approach}

The optimal diagnostic modality for accurately diagnosing PNETs is a pancreatic protocol computed tomographic (CT) scan. This helps characterize vascular involvement, staging, aberrant arterial anatomy, pancreatic and biliary duct abnormalities, and adjacent organ involvement (11). Even though diffusion-weighted imaging with magnetic resonance imaging (MRI) can contribute to PNET detection and provide some information about tumor grading (i.e. high-grade tumors have more restricted diffusion) (12), pathological examination of biopsies most commonly obtained using endoscopic ultrasound (EUS) is the gold standard (13).

Since $40-80 \%$ of patients with PNET have metastatic disease at presentation, most commonly to the liver (40$93 \%$ ), proper evaluation of the patient for hepatic metastasis is crucial $(14,15)$. One distinct advantage of the pancreatic protocol CT scan is that it does not interfere with this crucial assessment of liver metastases, since the arterial and portal venous phases match those recommended for liver imaging (16). The arterial phase is particularly important since PNET liver metastases predominantly receive blood from the hepatic arteries (11). However, the optimal imaging study for 
Table I. Classification and grading criteria for pancreatic neuroendocrine tumors (23).

\begin{tabular}{|c|c|c|c|c|}
\hline Terminology & Differentiation & Grade & Mitotic rate (mitoses $/ 2 \mathrm{~mm}^{2}$ ) & Ki-67 index \\
\hline NET, G1 & \multirow[t]{3}{*}{ Well-differentiated } & Low & $<2$ & $<3 \%$ \\
\hline NET, G2 & & Intermediate & $2-20$ & $3-20 \%$ \\
\hline NET, G3 & & High & $>20$ & $>20 \%$ \\
\hline NEC, small-cell type & \multirow[t]{2}{*}{ Poorly differentiated } & High & $>20$ & $>20 \%$ \\
\hline NEC, large-cell type & & & & \\
\hline MiNEN & Well or poorly differentiated* & Variable* & Variable* & Variable* \\
\hline
\end{tabular}

MiNEN: Mixed neuroendocrine non-neuroendocrine neoplasm; NEC: neuroendocrine carcinoma; NET: neuroendocrine tumor. *In most MiNENs, both the neuroendocrine and non-neuroendocrine components are poorly differentiated, and the neuroendocrine component has proliferation indices in the same range as other NECs, but this conceptual category allows for the possibility that one or both components may be well-differentiated; when feasible, each component should therefore be graded separately.

the assessment of liver metastases is a hepatobiliary-phase MRI with gadoxetate disodium because of its high measurement consistency and detection sensitivity (17-19).

Evaluation of lymph node involvement is also important for patients with PNET. A study of 326 patients undergoing PNET resection at the National Institutes of Health and Stanford University Hospital showed that $52 \%$ had lymph node involvement at the time of surgery (20). Both CT and MRI can detect lymph node involvement but are dependent on size criteria for characterization. Somatostatin receptor (SSTR)-based positron-emission tomography (PET) scan has revolutionized the diagnostic approach for PNETs and should be obtained if concerning lymph nodes are identified on conventional imaging studies. A chest CT scan should be obtained if SSTR-PET is not obtained at the time of initial presentation (11).

\section{PNET Grading}

One of the most important factors determining PNET management is tumor grade, which is determined using measures of tumor proliferation (mitotic index and Ki-67). Prior to 2017, well-differentiated PNETs were subdivided into low-grade (grade 1; Ki-67 index <3\%) and intermediate-grade (grade 2; Ki-67 index 3-20\%), while poorly differentiated were classified as high-grade: grade 3; Ki-67 index $>20 \%$. However, over time, researchers identified that some grade 3 PNETs are well-differentiated with a relatively good prognosis and response to platinum-based chemotherapy $(21,22)$. Realizing that not all grade 3 PNETs behave poorly, the World Health Organization decided to revisit this grading system.

PNET classification is based on the 2017 and 2019 World Health Organization neuroendocrine tumors classification (Table I) (23). Yang et al. published a study of 480 patients with PNETs who underwent resection between 2002-2018 and reported that the 5-year overall survival for those with grade 1 PNETs was $75.8 \%$, grade 2 PNETs was $58.4 \%$, grade 3 PNETs was $35.1 \%$, and grade 3 pancreatic neuroendocrine carcinoma (NEC) was $11.1 \%$ (23). According to the North American Neuroendocrine
Tumor Society (NANETS) guidelines, patients with poorly differentiated NEC should not be considered as surgical candidates due to the aggressive disease biology and poor prognosis of NECs (11). In contrast, patients with localized, welldifferentiated grade 3 PNETs can be considered for resection in the context of multimodal treatment, such as neoadjuvant therapy (11). In particular, further research of the operative and nonoperative options for grade 3 PNETs is warranted.

\section{PNET Staging}

Another equally important factor involved in the decisionmaking process of PNET management is tumor staging. Despite the prior differences between Europe and the United States, the most recent and widely used staging system is the Tumor, Node, Metastasis (TNM) classification of the American Joint Committee on Cancer/Union for International Cancer Control staging system $\left(8^{\text {th }}\right.$ edition, 2017) (Table II) (24). This staging system is based on the definitions proposed by the European Neuroendocrine Tumor Society (ENETS) (24) and is prognostic for survival $(2,25,26)$. In 2018, Li et al. performed a Surveillance, Epidemiology, and End Results database analysis of 2,350 patients who underwent oncological resection between 2004-2014 (2). They showed that the 5-year overall survival rate for patients with stage I PNETs was $89.9 \%$, for stage II PNETs was $82.6 \%$, for stage III PNETs was $75.8 \%$, and for stage IV PNETs was $56.9 \%$ (2). Although no definitive consensus was reached among the experts in the NANETS guidelines, the majority deemed there to be a benefit of primary tumor resection in cases with unresectable metastatic disease (11). Furthermore, they identified the most important factors to take into account during the decision-making process as tumor functionality, location (pancreatic head lesion resection is associated with greater morbidity and recovery time than resection of body or tail tumors), patient age (younger patients are better surgical candidates than older patients), comorbidities, potential local complications, and the possibility to improve response to other therapies (e.g., PRRT) (11). 
Table II. American Joint Committee on Cancer/Union for International Cancer Control Tumor, Node, Metastasis Staging of pancreatic neuroendocrine tumors eighth edition (24).

\begin{tabular}{|c|c|c|c|}
\hline \multicolumn{4}{|c|}{ Primary tumor $(\mathrm{T})$} \\
\hline $\mathrm{TX}$ & \multicolumn{3}{|c|}{ Tumor cannot be assessed } \\
\hline $\mathrm{T} 1$ & \multicolumn{3}{|c|}{ Tumor limited to the pancreas, $<2 \mathrm{~cm}$} \\
\hline $\mathrm{T} 2$ & \multicolumn{3}{|c|}{ Tumor limited to the pancreas $2-4 \mathrm{~cm}$} \\
\hline $\mathrm{T} 3$ & \multicolumn{3}{|c|}{ Tumor limited to the pancreas, $>4 \mathrm{~cm}$; or tumor invading the duodenum or common bile duct } \\
\hline $\mathrm{T} 4$ & \multicolumn{3}{|c|}{$\begin{array}{l}\text { Tumor invading adjacent organs (e.g., stomach, spleen, colon, adrenal gland) or } \\
\text { the wall of large vessels (celiac axis or the superior mesenteric artery) }\end{array}$} \\
\hline \multicolumn{4}{|c|}{ Regional lymph nodes $(\mathrm{N})$} \\
\hline NX & \multicolumn{3}{|c|}{ Regional lymph nodes cannot be assessed } \\
\hline No & \multicolumn{3}{|c|}{ No regional lymph node involvement } \\
\hline $\mathrm{N} 1$ & \multicolumn{3}{|c|}{ Regional lymph node involvement } \\
\hline \multicolumn{4}{|c|}{ Distant metastasis (M) } \\
\hline M0 & \multicolumn{3}{|l|}{ No distant metastasis } \\
\hline M1 & \multicolumn{3}{|l|}{ Distant metastases } \\
\hline M1a & \multicolumn{3}{|c|}{ Metastasis confined to liver } \\
\hline M1b & \multicolumn{3}{|c|}{ Metastases in at least one extrahepatic site (e.g., lung, ovary, nonregional lymph node, peritoneum, bone) } \\
\hline M1c & \multicolumn{3}{|c|}{ Both hepatic and extrahepatic metastases } \\
\hline \multicolumn{4}{|c|}{ Prognostic stage groups } \\
\hline Stage I & $\mathrm{T} 1$ & No & M0 \\
\hline Stage II & $\mathrm{T} 2 / \mathrm{T} 3$ & No & M0 \\
\hline Stage III & $\mathrm{T} 4$ & No & M0 \\
\hline Stage III & Any $\mathrm{T}$ & $\mathrm{N} 1$ & M0 \\
\hline Stage IV & Any $\mathrm{T}$ & Any $N$ & M1 \\
\hline
\end{tabular}

\section{Functional PNET}

The nomenclature of PNETs can be further influenced by the functionality of the tumor. Around $10-40 \%$ of PNETs are functional in that they secrete a predominant hormone, resulting in a clinical syndrome $(5,27)$. Functional PNETs are also typically well-differentiated. The surgical management for functional lesions relies on two main pillars: Symptom control and improved survival by limiting disease progression (11). Once the PNET is properly classified, graded and staged, and the presence of multiple endocrine neoplasia type 1 (MEN1) and distant metastases are excluded, the next step is to localize the PNET. If the biochemical diagnosis or localization is challenging, then referral to a specialized center is indicated for further evaluation. As previously mentioned, this evaluation might include upper gastrointestinal endoscopy with EUS, pancreatic protocol CT scan, or MRI. If these modalities are still unrevealing, venous sampling or intra-arterial simulation testing may be useful $(28,29)$. SSTR-PET may also be considered for non-insulinoma PNETs. This has a reported sensitivity of $100 \%$ [ $95 \%$ confidence interval $(\mathrm{CI})=93-100 \%$ ], specificity of $57.1 \%(95 \% \mathrm{CI}=18.4-90.1 \%)$, and accuracy of 94.8\% for non-insulinoma PNETs, and a reported sensitivity of $22.2 \%(95 \% \mathrm{CI}=8.6-42.2)$, specificity of $33.3 \%$ (95\% CI=0.890.5 ), and accuracy of $23.3 \%$ for insulinomas (30). If the PNET is still not localized, surgical exploration with intraoperative ultrasound should be considered at an experienced center (11). Once the functional PNET is adequately localized, surgical resection is indicated according to both the NANETS and the ENETS guidelines (11). Insulinomas have a 5-10\% risk of malignancy (31). However, there is a markedly increased risk of $60-90 \%$ malignancy for PNETs secreting glucagon, gastrin, vasoactive intestinal peptide, parathyroid hormone-related protein, or ectopic adrenocorticotrophic hormone $(5,11,27,32)$. The biochemical cure rate for resected localized insulinoma is $93-100 \%$ and the risk of recurrence is $7.2 \%(5,33)$. On the other hand, the biochemical cure rate for resected gastrinomas is $30-50 \%$, with a 15-year disease-related survival of $98 \%$ (34-38). Unfortunately, the cure rates for more aggressive PNETs, including glucagonoma, and those secreting vasoactive intestinal peptide, parathyroid hormone-related protein, or ectopic adrenocorticotrophic hormone are significantly lower $(11,39)$. Although mostly investigated in the setting of nonfunctional PNET, regional lymphadenectomy can be considered during surgical resection since evidence from resected gastrinomas suggests an increase in the chance for biochemical cure and improved survival $(20,40)$.

\section{Non-functional PNET}

The majority of PNETs (75-90\%) do not secrete a hormone and are therefore categorized as non-functional $(3,4)$. Because of their association with few symptoms, most non-functional PNETs have an indolent natural history and are diagnosed at more advanced stages, either incidentally or during workup for 
pain or compression symptoms $(1,39)$. Since non-functional PNETs $>2 \mathrm{~cm}$ are associated with a higher probability of lymph node involvement, poor tumor differentiation, metastasis, and worse outcomes $(41,42)$, both the NANETS and the ENETS guidelines recommend surgical resection. This holds true even if that means a radical operation with resection of adjacent organs and vascular reconstruction (43). On the other hand, the management of non-functional PNETs $<2 \mathrm{~cm}$ is more controversial. The NANETS guidelines recommend observation for non-functional PNETs $<1 \mathrm{~cm}$ and a patientoriented management for those $1-2 \mathrm{~cm}$ depending on age, comorbidities, grade, growth, extent of the required operation, and patient preference (11). The ENETS (5) and the National Comprehensive Cancer Network guidelines (44) state that observation of non-functional PNETs $\leq 2 \mathrm{~cm}$ with EUS, MRI, or CT scan, every 6-12 months is a reasonable option.

However, the argument for resecting non-functional PNETs $<2 \mathrm{~cm}$ is becoming more supported by a growing body of evidence that shows a relative risk of disease progression and nodal disease. Haynes and colleagues identified that $7.7 \%$ $(n=3 / 39)$ of patients who underwent resection of incidental non-functional PNETs $<2 \mathrm{~cm}$ developed late metastases or recurrence (45). Furthermore, a National Cancer Database analysis of patients diagnosed with PNETs $<2 \mathrm{~cm}$ between 1998 and 2006 comparing 309 who underwent resection and 71 observation showed an increased risk of death for the observation group in both univariate analysis (5-year overall survival: $34.3 \% \quad v s .82 .2 \%$ ) and multivariate analysis (adjusted hazard ratio $=2.80,95 \% \mathrm{CI}=1.28-6.16, p=0.01$ ) (46). Similarly, a meta-analysis of 11 studies demonstrated an increased risk of overall mortality in patients with PNETs $\leq 2$ $\mathrm{cm}$ who were observed compared with those who underwent resection at 3 years (risk ratio $=1.70,95 \% \mathrm{CI}=1.27-2.26$, $p<0.001$ ) and 5 years (risk ratio $=2.21,95 \% \mathrm{CI}=1.75-2.79$, $p<0.001)$ (47). Moreover, another National Cancer Database analysis on localized, well-differentiated, non-functional PNETs diagnosed in the United States between 2004-2015 showed that surgery was associated with improved overall survival for patients with tumors $1-2 \mathrm{~cm}$ and $>2 \mathrm{~cm}$ but not for those with tumors $<1 \mathrm{~cm}$, when adjusted for covariates (48). Dong et al. used international multi-institutional data and reported that patients with PNETs measuring $1.5-2 \mathrm{~cm}$ had a higher incidence of lymph node metastases (17.9\% vs. 8.7\%), higher Ki-67 index (>3\%: $35.9 \%$ vs. 18.8\%), worse tumor grade (grade 2: $29.2 \%$ vs. 13.9\%), and higher recurrence risk $(8.0 \%$ vs. $4.5 \%)$ following curative-intent resection compared with patients with PNETs measuring $<1.5$ $\mathrm{cm}$. Therefore, they suggested that patients with nonfunctional PNETs measuring 1.5-2 cm should be strongly considered for surgical resection (49). Notably, another multiinstitutional study from France showed that the cutoff of 2 $\mathrm{cm}$ used for malignancy for non-functional PNETs might need to be reduced to $1.7 \mathrm{~cm}$ to ensure more accurate patient selection (50). Overall, there are numerous studies suggesting benefit in resecting non-functional PNETs $<2 \mathrm{~cm}$.

On the contrary, there is also evidence supporting the nonoperative management of small non-functional PNETs. Lee et al. compared 77 observed vs. 56 resected cases with PNETs $<4 \mathrm{~cm}$ and reported no disease-specific progression or mortality in either group, while $46 \%$ of the resected cases had at least one postoperative complication (51). Sadot et al. also compared 104 observed versus 77 resected cases with PNETs $<3 \mathrm{~cm}$ and showed that at a median of 30 months, 26 ( $25 \%)$ of the observed patients required resection $(65 \%$ by patient or physician preference, $31 \%$ due to increased tumor size), and none of the 26 patients died or developed metastases after a median follow-up of 6.6 years (52). Similarly, a systematic review of five studies comparing 327 observed versus 213 resected cases reported that 46 (14.1\%) of the observed patients required resection, with the most common reason being an increase in tumor size $(n=19 / 46)$, while no disease-related mortality or distant metastasis was reported in the observed group in any of the five studies; the median length of follow-up ranged from 28 to 45 months (53). A 2021 interim analysis of a prospective PANDORA study from the Dutch Pancreatic Cancer Group demonstrated that $89 \%(n=68 / 76)$ of patients with a non-functional PNET $\leq 2 \mathrm{~cm}$ had no disease progression at a median follow-up of 17 months during watchful waiting (54). Although four mortalities were reported, all of them were unrelated to PNET, suggesting that well-selected patients with a nonfunctional PNET $<2 \mathrm{~cm}$ can be safely managed with observation (54). Despite the growing evidence for resection of non-functional PNETs $<2 \mathrm{~cm}$, there are still several studies suggesting a watchful waiting approach.

Although further evidence is required to definitively determine the appropriateness of observation versus surgical resection for small non-functional PNETs, conducting a randomized clinical trial would be particularly difficult since survival is long in these patients, requiring protracted followup. Nevertheless, a prospective observational study by ENETS is currently recruiting patients at IRCCS San Raffaele Hospital, Italy (NCT03084770). Patients will undergo active surveillance with MRI, CT scan, 68Galabeled PET/CT scan, and/or EUS every 6 months for 2 years, followed by annual imaging for 5 years. This surveillance group will be compared with patients undergoing surgical resection for asymptomatic small pancreatic endocrine neoplasms (ASPEN trial) $\leq 2 \mathrm{~cm}$. The primary outcome of this study is disease-free survival, while the secondary outcomes include morbidity and mortality after surgical resection, number of patients requiring surgery, type of surgery, PNET evolution and growth, and quality of life. Given the observational nature of the study, the findings of the ASPEN trial may be subject to potential selection bias but will still provide further insight into the argument of 


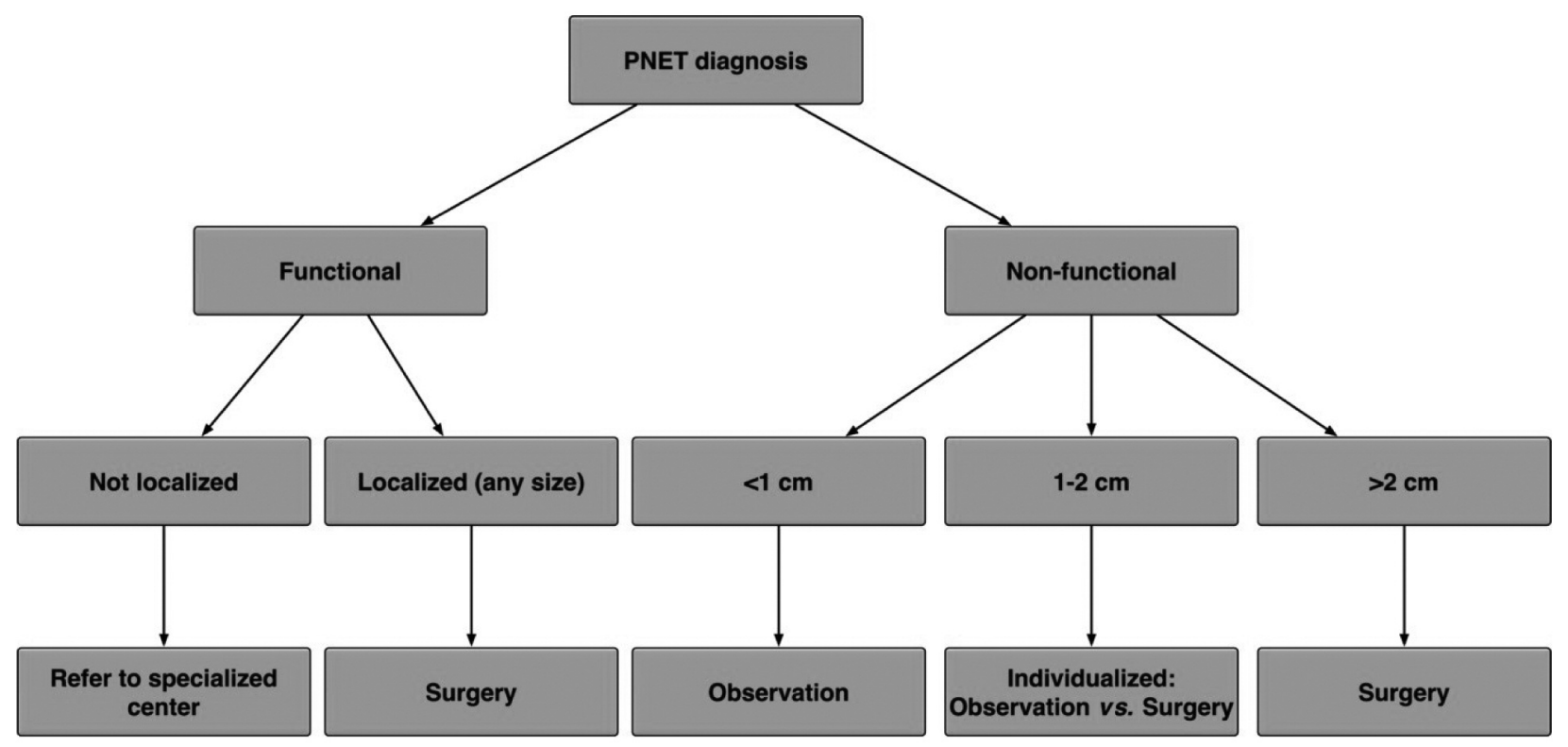

Figure 1. Proposed treatment algorithm for pancreatic neuroendocrine tumors (PNETS).

surgery versus observation for non-functional PNETs $<2 \mathrm{~cm}$. Until then, the proposed management algorithm is provided in Figure 1.

\section{PNET in MEN1}

Although MEN1 is seen in 20-60\% of patients with ZollingerEllison syndrome, more than $60 \%$ of patients with MEN1 have either Zollinger-Ellison syndrome or asymptomatic hypergastrinemia (55). In addition, radiographically confirmed, non-functional PNETs and gastrinomas have a prevalence of $30-80 \%$ in patients with MEN1 (56-59). In fact, the DutchMEN Study Group evaluated MEN1 patients using pancreatic imaging in a population-based cohort and demonstrated that five out of 350 patients developed clinically significant non-functional PNETs before entering adulthood and the actual risk was $1 \%$ at a median of 9.5 years $(95 \%$ $\mathrm{CI}=6.5-12.7), 2.5 \%$ at a median of 13.5 years $(95 \% \mathrm{CI}=10.2-$ $16.9)$, and $5 \%$ at a median of 17.8 years $(95 \% \mathrm{CI}=14.3-21.4)$ (60). Therefore, the authors recommended starting active surveillance with annual EUS, CT, MRI scans for nonfunctional PNETs with pancreatic imaging at the age of 13-14 years in patients with MEN1 (60).

Low-risk patients with MEN1 and functional PNETs should generally undergo surgical resection according to tumor size and disease extent. However, given the frequent multiplicity of PNETs in these patients, determining definitively that the identified PNET is the actual source of hormone overproduction may be challenging (11). That is particularly challenging for gastrinomas since hypergastrinemia in patients with MEN1 is more likely to arise from duodenal gastrinomas rather than from PNETs. Therefore, medical versus. surgical management of patients with MEN1 with hypergastrinemia has been controversial since gastrinomas in these patients are typically small, multiple, and difficult to image. In addition, controlling hypergastrinemia with surgery has been challenging to achieve $(36,61)$. In fact, the NANETS guidelines recommend the use of EUS to determine the presence of multifocal disease in patients with MEN1 (11). Surgery is a reasonable option for those with MEN1 with hypergastrinemia and lymph node metastasis, poorly controlled symptoms, and PNET-dominant disease (11). For those with non-functional PNETs, the NANETS guidelines recommend resection of tumors $>2 \mathrm{~cm}$ and observation of tumors $<1 \mathrm{~cm}$. Management of non-functional PNETs 1-2 cm in size should be individualized based on symptoms, tumor grade, growth rate or radiographic progression, family history, and comorbid conditions (11).

\section{Extent of Surgery for PNET and Postoperative Outcomes}

Surgical resection for PNETs can range from parenchymasparing operations, such as enucleation and central pancreatectomy, to major demolitive operations, such as pancreaticoduodenectomy, distal pancreatectomy, or even total pancreatectomy (Figure 2) (62). The decision on the extent of surgery is based on tumor location, size, grade, and 


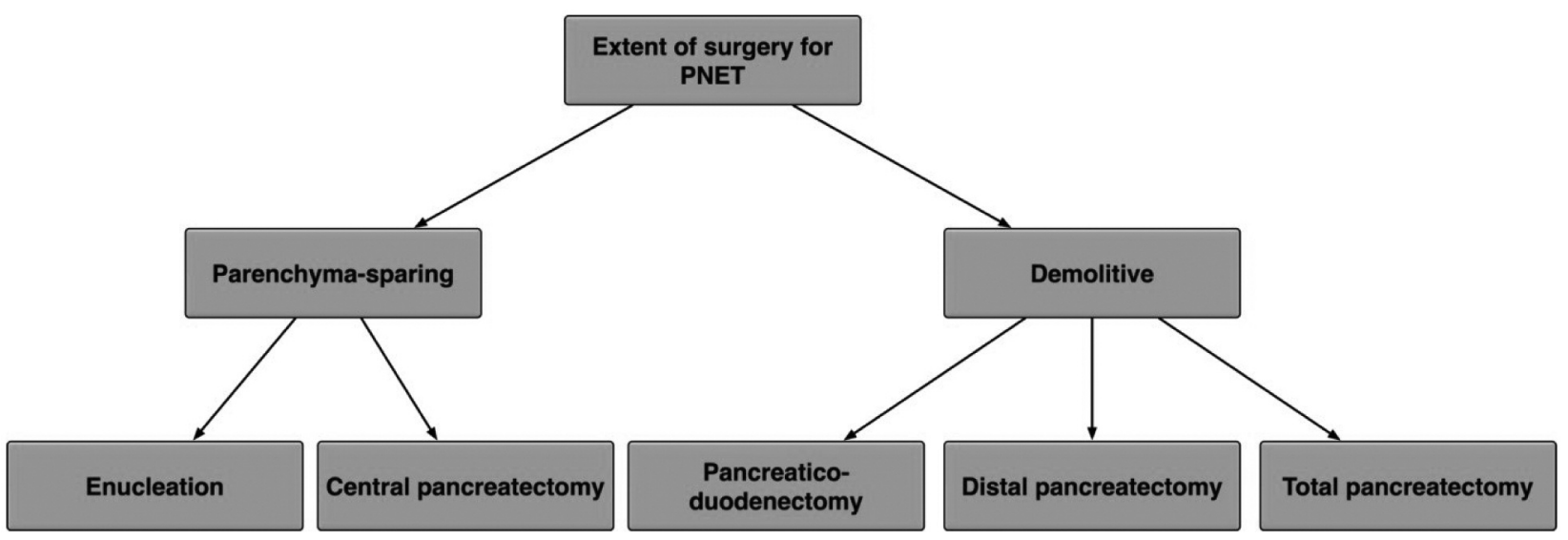

Figure 2. Extent of pancreatic surgery for pancreatic neuroendocrine tumors (PNETs).

risk of nodal involvement (63). Parenchyma-sparing surgery can be an option for small, low-grade PNETs (e.g., nonfunctional PNETs $<2 \mathrm{~cm}$ or insulinomas), while for patients with large or high-grade PNETs or with increased risk of nodal involvement, demolitive surgery with regional lymphadenectomy should be preferred (11). For PNETs at the body or tail of the pancreas, spleen-preserving distal pancreatectomy may be considered for small presumably benign tumors, depending on the association of the PNET with the splenic vasculature and hilum (63).

Overall, no major difference in postoperative morbidity has been reported after enucleation versus central pancreatectomy for PNETs (64-67). Although parenchymapreserving resections and demolitive resections for PNETs have similar reported rates of postoperative hemorrhage and delayed gastric emptying, the rate of postoperative pancreatic fistula is higher after parenchyma-preserving resections, and particularly after enucleation (66-69). On the other hand, demolitive operations, particularly pancreaticoduodenectomy and total pancreatectomy, are associated with increased rates of diabetes mellitus and exocrine pancreatic insufficiency compared with parenchyma-sparing resections $(67,69)$.

A multicenter study from the United States showed that the extent of curative pancreatic resection for PNETs was not associated with the status of surgical margins in that all types of pancreatic surgery had similar R1 rates. The authors concluded that parenchyma-sparing resections of PNETs with minimal margins may be appropriate in well-selected patients (70). In fact, similar survival outcomes have been reported in several studies between parenchyma-sparing pancreatic surgery and more aggressive oncologic resections for PNETs $(65,66,71)$. However, the importance of lymph node sampling during parenchyma-sparing resections should be emphasized to avoid understaging (64). Of note, the NANETS guidelines recommend parenchyma-sparing surgery particularly for patients with familial PNETs to preserve pancreatic endocrine and exocrine functions (11).

\section{Minimally Invasive Surgery for PNET}

The introduction of minimally invasive surgical approaches in the operative management of hepato-pancreato-biliary neoplasms has also emerged for PNETs. Specifically, several series worldwide have demonstrated the safety and feasibility of laparoscopic distal pancreatectomy and enucleation for insulinomas (72-74), even in patients with MEN1 (75). A growing body of evidence has demonstrated favorable outcomes of minimally invasive pancreatic surgery compared with the conventional open approach for PNETs in terms of shorter operative time, reduced blood loss, and shorter hospital stay, with equivalent or even lower complication rates and incidence of recurrence (76-78). Notably, robotic pancreatic surgery is also being implemented more and more frequently for the resection of PNETs, ranging from enucleation of PNETs of the uncinate process (79) to total pancreatectomy for diffuse PNET in the head, body, and tail (80) or even multivisceral resection for PNET with synchronous liver metastasis (81).

\section{PNET with Liver Metastases}

Depending on the presentation and extent of metastatic disease to the liver, different surgical or medical treatment options may be utilized (14). Evidence has shown that cytoreduction of PNET liver metastases can lead to improved symptoms and survival (82-84). Cytoreduction is more likely offered to patients with favorable or limited disease and it can delay the cause of death in patients with liver metastases, which is liver failure secondary to liver replacement by the tumor. Initially, it was thought that more than $90 \%$ cytoreduction is required to achieve a favorable outcome but more recent data from both 
Table III. Liver transplantation criteria for patients with pancreatic neuroendocrine tumors with liver metastases (90).

\begin{tabular}{ll}
\hline Milan-NET criteria & UNOS recommendations \\
\hline Absolute & Criteria common to Milan-NET \\
- Histological grade 1 or 2 & - Histological grade 1 or 2 \\
- Portal drainage of the primary tumor & - Tumors of gastro-entero-pancreatic origin with portal system drainage \\
- Hepatic tumor invasion $<50 \%$ & - Tumor replacement $<50 \%$ of the liver volume \\
- Pre-transplant curative resection of all extrahepatic lesions & - Resection of primary and extra-hepatic disease without recurrence $>6$ months \\
- Duration of stable disease $>6$ months & - Recipient age $<60$ years \\
Relative & Additional criteria \\
- Age $<60$ years & - Unresectable liver metastases \\
& - Radiographic characteristics of NET of the liver lesions \\
& - Negative metastatic workup by PET scan \\
& - Lack of extrahepatic tumor recurrence during the previous 3 months \\
& - In the presence of positive findings for lymph node metastases by \\
& PET scan, the finding should become negative for 6 months before re-listing \\
& - In the presence of extrahepatic solid organ metastases \\
& (i.e., lungs or bones), the case will be permanently delisted
\end{tabular}

NET: Neuroendocrine tumor; PET: positron-emission tomography; UNOS: United Network for Organ Sharing.

gastrointestinal neuroendocrine tumors and PNETs have demonstrated that little benefit is achieved once $70 \%$ of the PNET liver metastases are cytoreduced (85-87). Although the current level of evidence is still low, most experts believe that a patient-oriented approach should be adopted according to the number and distribution of lesions, age, comorbidities, grade, and rate of progression, and that $70 \%$ cytoreduction can improve symptom control and survival (11). For patients who are not candidates for cytoreduction, medical management has shown significant progress and options include somatostatin analogs, molecularly targeted therapy (e.g., everolimus or sunitinib), cytotoxic chemotherapy (e.g., capecitabine and temozolomide), immunotherapy, and PRRT (14, 88, 89).

Liver transplantation may also be an option for well-selected patients with PNETs and unresectable liver metastases (Table III) (90). Although the overall survival outcomes posttransplant are favorable, with a 5-year rate of $47-71 \%$, the main issue is the high rate of recurrence post-transplant (31-57\%) which warrants further research to identify prognostic factors and optimize patient selection (90-92).

\section{Conclusion}

Overall, according to the current body of evidence, surgical resection is a reasonable option for well-selected patients with functional PNETs of any size or non-functional PNETs $>2 \mathrm{~cm}$. For patients with non-functional PNETs $1-2 \mathrm{~cm}$, a patientoriented approach should be used based upon age, comorbidities, tumor location, differentiation, and staging. Ongoing research will give further insight into how better to select surgical candidates for PNET resection, to determine whether observation or resection is appropriate for non-functional PNETs $1-2 \mathrm{~cm}$, and to improve patient outcomes and quality of life.

\section{Conflicts of Interest}

No conflicts of interest.

\section{Authors' Contributions}

IA Ziogas, R Schmitz, D Moris, and CJ Vatsaas conceived and designed the study, acquired, analyzed, and interpreted the data, drafted, and critically revised the article, and approved the final version of the article.

\section{References}

1 Sauvanet A: Gastroenteropancreatic neuroendocrine tumors: Role of surgery. Ann Endocrinol (Paris) 80(3): 175-181, 2019. PMID: 31079831. DOI: 10.1016/j.ando.2019.04.009

$2 \mathrm{Li} \mathrm{X}$, Gou S, Liu Z, Ye Z and Wang C: Assessment of the American Joint Commission on cancer 8th edition staging system for patients with pancreatic neuroendocrine tumors: a surveillance, epidemiology, and end results analysis. Cancer Med 7(3): 626-634, 2018. PMID: 29380547. DOI: 10.1002/cam4.1336

3 Halfdanarson TR, Rabe KG, Rubin J and Petersen GM: Pancreatic neuroendocrine tumors (PNETs): incidence, prognosis and recent trend toward improved survival. Ann Oncol 19(10): 1727-1733, 2008. PMID: 18515795 . DOI: $10.1093 /$ annonc/mdn351

4 Zerbi A, Falconi M, Rindi G, Delle Fave G, Tomassetti P, Pasquali C, Capitanio V, Boninsegna L, Di Carlo V and AISPNetwork Study Group: Clinicopathological features of pancreatic endocrine tumors: a prospective multicenter study in Italy of 297 sporadic cases. Am J Gastroenterol 105(6): 1421-1429, 2010. PMID: 20087335. DOI: 10.1038/ajg.2009.747

5 Falconi M, Eriksson B, Kaltsas G, Bartsch DK, Capdevila J, Caplin M, Kos-Kudla B, Kwekkeboom D, Rindi G, Klöppel G, Reed N, Kianmanesh R, Jensen RT and Vienna Consensus Conference participants: ENETS consensus guidelines update for the management of patients with functional pancreatic neuroendocrine tumors and non-functional pancreatic neuroendocrine tumors. 
Neuroendocrinology 103(2): 153-171, 2016. PMID: 26742109 DOI: $10.1159 / 000443171$

6 Dasari A, Shen C, Halperin D, Zhao B, Zhou S, Xu Y, Shih T and Yao JC: Trends in the incidence, prevalence, and survival outcomes in patients with neuroendocrine tumors in the United States. JAMA Oncol 3(10): 1335-1342, 2017. PMID: 28448665. DOI: 10.1001/jamaoncol.2017.0589

7 Yao JC, Hassan M, Phan A, Dagohoy C, Leary C, Mares JE, Abdalla EK, Fleming JB, Vauthey JN, Rashid A and Evans DB: One hundred years after "carcinoid": epidemiology of and prognostic factors for neuroendocrine tumors in 35,825 cases in the United States. J Clin Oncol 26(18): 3063-3072, 2008. PMID: 18565894. DOI: $10.1200 / \mathrm{JCO} .2007 .15 .4377$

$8 \mathrm{Hu} \mathrm{Y,} \mathrm{Ye} \mathrm{Z,} \mathrm{Wang} \mathrm{F,} \mathrm{Qin} \mathrm{Y,} \mathrm{Xu} \mathrm{X,} \mathrm{Yu} \mathrm{X} \mathrm{and} \mathrm{Ji} \mathrm{S:} \mathrm{Role} \mathrm{of}$ somatostatin receptor in pancreatic neuroendocrine tumor development, diagnosis, and therapy. Front Endocrinol (Lausanne) 12: 679000, 2021. PMID: 34093445. DOI: 10.3389/fendo.2021. 679000

9 Pellat A, Cottereau AS, Palmieri LJ, Soyer P, Marchese U, Brezault $\mathrm{C}$ and Coriat R: Digestive well-differentiated grade 3 neuroendocrine tumors: Current management and future directions. Cancers (Basel) 13(10): 2448, 2021. PMID: 34070035. DOI: $10.3390 /$ cancers 13102448

10 Camus B, Cottereau AS, Palmieri LJ, Dermine S, Tenenbaum F, Brezault $\mathrm{C}$ and Coriat $\mathrm{R}$ : Indications of peptide receptor radionuclide therapy (PRRT) in gastroenteropancreatic and pulmonary neuroendocrine tumors: an updated review. J Clin Med 10(6): 1267, 2021. PMID: 33803817. DOI: 10.3390/jcm10061267

11 Howe JR, Merchant NB, Conrad C, Keutgen XM, Hallet J, Drebin JA, Minter RM, Lairmore TC, Tseng JF, Zeh HJ, Libutti SK, Singh G, Lee JE, Hope TA, Kim MK, Menda Y, Halfdanarson TR, Chan JA and Pommier RF: The North American Neuroendocrine Tumor Society consensus paper on the surgical management of pancreatic neuroendocrine tumors. Pancreas 49(1): 1-33, 2020. PMID: 31856076. DOI: 10.1097/MPA.0000000000001454

12 Lotfalizadeh E, Ronot M, Wagner M, Cros J, Couvelard A, Vullierme MP, Allaham W, Hentic O, Ruzniewski P and Vilgrain $V$ : Prediction of pancreatic neuroendocrine tumour grade with MR imaging features: added value of diffusion-weighted imaging. Eur Radiol 27(4): 1748-1759, 2017. PMID: 27543074. DOI: $10.1007 / \mathrm{s} 00330-016-4539-4$

13 James PD, Tsolakis AV, Zhang M, Belletrutti PJ, Mohamed R, Roberts DJ and Heitman SJ: Incremental benefit of preoperative EUS for the detection of pancreatic neuroendocrine tumors: a meta-analysis. Gastrointest Endosc 81(4): 848-56.e1, 2015. PMID: 25805462. DOI: 10.1016/j.gie.2014.12.031

14 Nigri G, Petrucciani N, Debs T, Mangogna LM, Crovetto A, Moschetta G, Persechino R, Aurello P and Ramacciato G: Treatment options for PNET liver metastases: a systematic review. World J Surg Oncol 16(1): 142, 2018. PMID: 30007406. DOI: $10.1186 / \mathrm{s} 12957-018-1446-\mathrm{y}$

15 Tsilimigras DI, Ntanasis-Stathopoulos I, Kostakis ID, Moris D, Schizas D, Cloyd JM and Pawlik TM: Is resection of primary midgut neuroendocrine tumors in patients with unresectable metastatic liver disease justified? A systematic review and metaanalysis. J Gastrointest Surg 23(5): 1044-1054, 2019. PMID: 30671800. DOI: 10.1007/s11605-018-04094-9

16 Kambadakone AR, Fung A, Gupta RT, Hope TA, Fowler KJ, Lyshchik A, Ganesan K, Yaghmai V, Guimaraes AR, Sahani DV and Miller FH: LI-RADS technical requirements for CT, MRI, and contrast-enhanced ultrasound. Abdom Radiol (NY) 43(1): 56-74, 2018. PMID: 28940042. DOI: 10.1007/s00261-017-1325-y

17 Morse B, Jeong D, Thomas K, Diallo D and Strosberg JR: Magnetic resonance imaging of neuroendocrine tumor hepatic metastases: Does hepatobiliary phase imaging improve lesion conspicuity and interobserver agreement of lesion measurements? Pancreas 46(9): 1219-1224, 2017. PMID: 28902795. DOI: 10.1097/MPA.0000000000000920

18 Tirumani SH, Jagannathan JP, Braschi-Amirfarzan M, Qin L, Balthazar P, Ramaiya $\mathrm{NH}$ and Shinagare AB: Value of hepatocellular phase imaging after intravenous gadoxetate disodium for assessing hepatic metastases from gastroenteropancreatic neuroendocrine tumors: comparison with other MRI pulse sequences and with extracellular agent. Abdom Radiol (NY) 43(9): 2329-2339, 2018. PMID: 29470627. DOI: 10.1007/s00261-0181496-1

19 Balthazar P, Shinagare AB, Tirumani SH, Jagannathan JP, Ramaiya NH and Khorasani R: Gastroenteropancreatic neuroendocrine tumors: impact of consistent contrast agent selection on radiologists' confidence in hepatic lesion assessment on restaging MRIs. Abdom Radiol (NY) 43(6): 1386-1392, 2018. PMID: 28840281. DOI: 10.1007/s00261-017-1302-5

20 Krampitz GW, Norton JA, Poultsides GA, Visser BC, Sun L and Jensen RT: Lymph nodes and survival in pancreatic neuroendocrine tumors. Arch Surg 147(9): 820-827, 2012. PMID: 22987171. DOI: 10.1001/archsurg.2012.1261

21 Low SK, Giannis D, Bahaie NS, Trong BLH, Moris D and Huy NT: Competing mortality in patients with neuroendocrine tumors. Am J Clin Oncol 42(8): 668-674, 2019. PMID: 31343423. DOI: $10.1097 / C O C .0000000000000575$

22 Schmitz R, Mao R, Moris D, Strickler JH and Blazer DG 3rd: Impact of postoperative chemotherapy on the survival of patients with high-grade gastroenteropancreatic neuroendocrine carcinoma. Ann Surg Oncol 28(1): 114-120, 2021. PMID: 32556871. DOI: $10.1245 / \mathrm{s} 10434-020-08730-0$

23 Yang M, Zeng L, Ke NW, Tan CL, Tian BL, Liu XB, Xiang B and Zhang Y: World Health Organization grading classification for pancreatic neuroendocrine neoplasms: a comprehensive analysis from a large Chinese institution. BMC Cancer 20(1): 906, 2020. PMID: 32962649. DOI: 10.1186/s12885-020-07356-5

24 Rindi G, Klöppel G, Alhman H, Caplin M, Couvelard A, de Herder WW, Erikssson B, Falchetti A, Falconi M, Komminoth P, Körner M, Lopes JM, McNicol AM, Nilsson O, Perren A, Scarpa A, Scoazec JY, Wiedenmann B, all other Frascati Consensus Conference participants. and European Neuroendocrine Tumor Society (ENETS): TNM staging of foregut (neuro)endocrine tumors: a consensus proposal including a grading system. Virchows Arch 449(4): 395-401, 2006. PMID: 16967267. DOI: 10.1007/s00428-006-0250-1

25 Strosberg JR, Cheema A, Weber JM, Ghayouri M, Han G, Hodul PJ and Kvols LK: Relapse-free survival in patients with nonmetastatic, surgically resected pancreatic neuroendocrine tumors: an analysis of the AJCC and ENETS staging classifications. Ann Surg 256(2): 321-325, 2012. PMID: 22415420. DOI: 10.1097/SLA.0b013e31824e6108

26 Cho JH, Ryu JK, Song SY, Hwang JH, Lee DK, Woo SM, Joo YE, Jeong S, Lee SO, Park BK, Cheon YK, Han J, Kim TN, Lee JK, Moon SH, Kim H, Park ET, Hwang JC, Kim TH, Jeon TJ, Cho CM, Choi HS and Lee WJ: Prognostic validity of the American Joint Committee on Cancer and the European 
Neuroendocrine Tumors staging classifications for pancreatic neuroendocrine tumors: a retrospective nationwide multicenter study in South Korea. Pancreas 45(7): 941-946, 2016. PMID: 26765964. DOI: 10.1097/MPA.0000000000000586

27 Ito T, Igarashi $\mathrm{H}$ and Jensen RT: Pancreatic neuroendocrine tumors: clinical features, diagnosis and medical treatment: advances. Best Pract Res Clin Gastroenterol 26(6): 737-753, 2012. PMID: 23582916. DOI: 10.1016/j.bpg.2012.12.003

28 Doppman JL, Chang R, Fraker DL, Norton JA, Alexander HR, Miller DL, Collier E, Skarulis MC and Gorden P: Localization of insulinomas to regions of the pancreas by intra-arterial stimulation with calcium. Ann Intern Med 123(4): 269-273, 1995. PMID: 7611592. DOI: 10.7326/0003-4819-123-4199508150-00004

29 Sung YM, Do YS, Lee MK, Shin SW, Liu WC, Choo SW and Choo IW: Selective intra-arterial calcium stimulation with hepatic venous sampling for preoperative localization of insulinomas. Korean J Radiol 4(2): 101-108, 2003. PMID: 12845305. DOI: $10.3348 / \mathrm{kjr} .2003 .4 .2 .101$

30 Sharma P, Arora S, Dhull VS, Naswa N, Kumar R, Ammini AC and Bal C: Evaluation of (68)Ga-DOTANOC PET/CT imaging in a large exclusive population of pancreatic neuroendocrine tumors. Abdom Imaging 40(2): 299-309, 2015. PMID: 25134801. DOI: 10.1007/s00261-014-0219-5

31 Giannis D, Moris D, Karachaliou GS, Tsilimigras DI, Karaolanis G, Papalampros A and Felekouras E: Insulinomas: from diagnosis to treatment. A review of the literature. J BUON 25(3): 1302-1314, 2020. PMID: 32862570.

32 Schizas D, Mastoraki A, Bagias G, Patras R, Moris D, Lazaridis II, Arkadopoulos N and Felekouras E: Clinicopathological data and treatment modalities for pancreatic vipomas: a systematic review. J BUON 24(2): 415-423, 2019. PMID: 31127985.

33 Mehrabi A, Fischer L, Hafezi M, Dirlewanger A, Grenacher L, Diener MK, Fonouni H, Golriz M, Garoussi C, Fard N, Rahbari NN, Werner J and Büchler MW: A systematic review of localization, surgical treatment options, and outcome of insulinoma. Pancreas 43(5): 675-686, 2014. PMID: 24921202. DOI: $10.1097 / M P A .0000000000000110$

34 Norton JA, Fraker DL, Alexander HR, Gibril F, Liewehr DJ, Venzon DJ and Jensen RT: Surgery increases survival in patients with gastrinoma. Ann Surg 244(3): 410-419, 2006. PMID: 16926567. DOI: 10.1097/01.sla.0000234802.44320.a5

35 Howard TJ, Zinner MJ, Stabile BE and Passaro E Jr: Gastrinoma excision for cure. A prospective analysis. Ann Surg 211(1): 914, 1990. PMID: 2294850. DOI: 10.1097/00000658-19900100000002

36 Norton JA, Fraker DL, Alexander HR, Venzon DJ, Doppman JL, Serrano J, Goebel SU, Peghini PL, Roy PK, Gibril F and Jensen RT: Surgery to cure the Zollinger-Ellison syndrome. N Engl J Med 341(9): 635-644, 1999. PMID: 10460814. DOI: 10.1056/NEJM199908263410902

37 Norton JA, Alexander HR, Fraker DL, Venzon DJ, Gibril F and Jensen RT: Possible primary lymph node gastrinoma: occurrence, natural history, and predictive factors: a prospective study. Ann Surg 237(5): 650-7; discussion 657-9, 2003. PMID: 12724631. DOI: 10.1097/01.SLA.0000064375.51939.48

38 Norton JA, Alexander HR, Fraker DL, Venzon DJ, Gibril F and Jensen RT: Does the use of routine duodenotomy (DUODX) affect rate of cure, development of liver metastases, or survival in patients with Zollinger-Ellison syndrome? Ann Surg 239(5):
617-25; discussion 626, 2004. PMID: 15082965. DOI: 10.1097/01.sla.0000124290.05524.5e

39 Tsilimigras DI and Pawlik TM: Pancreatic neuroendocrine tumours: conservative versus surgical management. Br J Surg 108(11): 12671269, 2021. PMID: 34519788. DOI: 10.1093/bjs/znab232

40 Bartsch DK, Waldmann J, Fendrich V, Boninsegna L, Lopez CL, Partelli S and Falconi M: Impact of lymphadenectomy on survival after surgery for sporadic gastrinoma. Br J Surg 99(9): 1234-1240, 2012. PMID: 22864882. DOI: 10.1002/bjs.8843

41 Kim MJ, Choi DW, Choi SH, Heo JS, Park HJ, Choi KK, Jang KT and Sung JY: Surgical strategies for non-functioning pancreatic neuroendocrine tumours. Br J Surg 99(11): 15621568, 2012. PMID: 23027073. DOI: 10.1002/bjs.8892

42 Toste PA, Kadera BE, Tatishchev SF, Dawson DW, Clerkin BM, Muthusamy R, Watson R, Tomlinson JS, Hines OJ, Reber HA and Donahue TR: Nonfunctional pancreatic neuroendocrine tumors $<2 \mathrm{~cm}$ on preoperative imaging are associated with a low incidence of nodal metastasis and an excellent overall survival. J Gastrointest Surg 17(12): 2105-2113, 2013. PMID: 24101447. DOI: $10.1007 / \mathrm{s} 11605-013-2360-9$

43 Minter RM and Simeone DM: Contemporary management of nonfunctioning pancreatic neuroendocrine tumors. J Gastrointest Surg 16(2): 435-446, 2012. PMID: 22009463. DOI: 10.1007/s11605-011-1693-5

44 Aziz H, Howe JR and Pawlik TM: Surgery vs observation for patients with small pancreatic neuroendocrine tumors. JAMA Surg 156(5): 412-413, 2021. PMID: 33439231. DOI: 10.1001 /jamasurg.2020.5640

45 Haynes AB, Deshpande V, Ingkakul T, Vagefi PA, Szymonifka J, Thayer SP, Ferrone CR, Wargo JA, Warshaw AL and Fernández-del Castillo $\mathrm{C}$ : Implications of incidentally discovered, nonfunctioning pancreatic endocrine tumors: shortterm and long-term patient outcomes. Arch Surg 146(5): 534538, 2011. PMID: 21576607. DOI: 10.1001/archsurg.2011.102

46 Sharpe SM, In H, Winchester DJ, Talamonti MS and Baker MS: Surgical resection provides an overall survival benefit for patients with small pancreatic neuroendocrine tumors. J Gastrointest Surg 19(1): 117-23; discussion 123, 2015. PMID: 25155459. DOI: $10.1007 / \mathrm{s} 11605-014-2615-0$

47 Finkelstein P, Sharma R, Picado O, Gadde R, Stuart H, Ripat C, Livingstone AS, Sleeman D, Merchant $\mathrm{N}$ and Yakoub D: Pancreatic neuroendocrine tumors (panNETs): Analysis of overall survival of nonsurgical management versus surgical resection. J Gastrointest Surg 21(5): 855-866, 2017. PMID: 28255853. DOI: $10.1007 / \mathrm{s} 11605-017-3365-6$

48 Assi HA, Mukherjee S, Kunz PL, Machiorlatti M, Vesely S, Pareek $\mathrm{V}$ and Hatoum H: Surgery versus surveillance for well-differentiated, nonfunctional pancreatic neuroendocrine tumors: an 11-year analysis of the National Cancer Database. Oncologist 25(2): e276-e283, 2020. PMID: 32043766. DOI: 10.1634/theoncologist.2019-0466

49 Dong DH, Zhang XF, Poultsides G, Rocha F, Weber S, Fields R, Idrees K, Cho C, Maithel SK, Pawlik TM and other members of the US Neuroendocrine Tumor Study Group: Impact of tumor size and nodal status on recurrence of nonfunctional pancreatic neuroendocrine tumors $\leq 2 \mathrm{~cm}$ after curative resection: A multiinstitutional study of 392 cases. J Surg Oncol 120(7): 10711079, 2019. PMID: 31571225. DOI: 10.1002/jso.25716

50 Regenet N, Carrere N, Boulanger G, de Calan L, Humeau M, Arnault V, Kraimps JL, Mathonnet M, Pessaux P, Donatini G, Venara A, Christou N, Bachelier P, Hamy A and Mirallié E: Is the 
2-cm size cutoff relevant for small nonfunctioning pancreatic neuroendocrine tumors: A French multicenter study. Surgery 159(3): 901-907, 2016. PMID: 26590096. DOI: 10.1016/j.surg.2015.10.003

51 Lee LC, Grant CS, Salomao DR, Fletcher JG, Takahashi N, Fidler JL, Levy MJ and Huebner M: Small, nonfunctioning, asymptomatic pancreatic neuroendocrine tumors (PNETs): role for nonoperative management. Surgery 152(6): 965-974, 2012. PMID: 23102679. DOI: 10.1016/j.surg.2012.08.038

52 Sadot E, Reidy-Lagunes DL, Tang LH, Do RK, Gonen M, D'Angelica MI, DeMatteo RP, Kingham TP, Groot Koerkamp B, Untch BR, Brennan MF, Jarnagin WR and Allen PJ: Observation versus resection for small asymptomatic pancreatic neuroendocrine tumors: a matched case-control study. Ann Surg Oncol 23(4): 13611370, 2016. PMID: 26597365. DOI: 10.1245/s10434-015-4986-1

53 Partelli S, Cirocchi R, Crippa S, Cardinali L, Fendrich V, Bartsch DK and Falconi M: Systematic review of active surveillance versus surgical management of asymptomatic small non-functioning pancreatic neuroendocrine neoplasms. Br J Surg 104(1): 34-41, 2017. PMID: 27706803. DOI: 10.1002/bjs.10312

54 Heidsma CM, Engelsman AF, van Dieren S, Stommel MWJ, de Hingh I, Vriens M, Hol L, Festen S, Mekenkamp L, Hoogwater FJH, Daams F, Klümpen HJ, Besselink MG, van Eijck CH and Nieveen van Dijkum EJ: Watchful waiting for small nonfunctional pancreatic neuroendocrine tumours: nationwide prospective cohort study (PANDORA). Br J Surg 108(8): 888891, 2021. PMID: 33783475. DOI: 10.1093/bjs/znab088

55 Pipeleers-Marichal M, Somers G, Willems G, Foulis A, Imrie C, Bishop AE, Polak JM, Häcki WH, Stamm B and Heitz PU: Gastrinomas in the duodenums of patients with multiple endocrine neoplasia type 1 and the Zollinger-Ellison syndrome. N Engl J Med 322(11): 723-727, 1990. PMID: 1968616. DOI: 10.1056/NEJM199003153221103

56 Wamsteker EJ, Gauger PG, Thompson NW and Scheiman JM: EUS detection of pancreatic endocrine tumors in asymptomatic patients with type 1 multiple endocrine neoplasia. Gastrointest Endosc 58(4): 531-535, 2003. PMID: 14520285. DOI: $10.1067 / \mathrm{s} 0016-5107(03) 01965-5$

57 Thomas-Marques L, Murat A, Delemer B, Penfornis A, CardotBauters C, Baudin E, Niccoli-Sire P, Levoir D, Choplin Hdu B, Chabre O, Jovenin N, Cadiot $\mathrm{G}$ and Groupe des Tumeurs Endocrines (GTE): Prospective endoscopic ultrasonographic evaluation of the frequency of nonfunctioning pancreaticoduodenal endocrine tumors in patients with multiple endocrine neoplasia type 1. Am J Gastroenterol 101(2): 266-273, 2006. PMID: 16454829. DOI: 10.1111/j.1572-0241.2006.00367.x

58 Kouvaraki MA, Shapiro SE, Cote GJ, Lee JE, Yao JC, Waguespack SG, Gagel RF, Evans DB and Perrier ND: Management of pancreatic endocrine tumors in multiple endocrine neoplasia type 1. World J Surg 30(5): 643-653, 2006. PMID: 16680581. DOI: 10.1007/s00268-006-0360-y

59 Triponez F, Dosseh D, Goudet P, Cougard P, Bauters C, Murat A, Cadiot G, Niccoli-Sire P, Chayvialle JA, Calender A and Proye CA: Epidemiology data on 108 MEN 1 patients from the GTE with isolated nonfunctioning tumors of the pancreas. Ann Surg 243(2): 265-272, 2006. PMID: 16432361. DOI: 10.1097/01.sla.0000197715.96762.68

60 Klein Haneveld MJ, van Treijen MJC, Pieterman CRC, Dekkers OM, van de Ven A, de Herder WW, Zandee WT, Drent ML, Bisschop PH, Havekes B, Vriens MR, Verrijn Stuart AA, Valk GD and van Leeuwaarde RS: Initiating pancreatic neuroendocrine tumor
(pNET) screening in young MEN1 patients: Results from the DutchMEN study group. J Clin Endocrinol Metab 106(12): 35153525, 2021. PMID: 34333645. DOI: 10.1210/clinem/dgab569

61 Norton JA and Jensen RT: Resolved and unresolved controversies in the surgical management of patients with Zollinger-Ellison syndrome. Ann Surg 240(5): 757-773, 2004. PMID: 15492556. DOI: 10.1097/01 sla.0000143252.02142.3e

62 Bartolini I, Bencini L, Risaliti M, Ringressi MN, Moraldi L and Taddei A: Current management of pancreatic neuroendocrine tumors: from demolitive surgery to observation. Gastroenterol Res Pract 2018: 9647247, 2018. PMID: 30140282. DOI: $10.1155 / 2018 / 9647247$

63 Jeune F, Taibi A and Gaujoux S: Update on the surgical treatment of pancreatic neuroendocrine tumors. Scand J Surg 109(1): 42-52, 2020. PMID: 31975647. DOI: 10.1177/1457496919900417

64 Falconi M, Zerbi A, Crippa S, Balzano G, Boninsegna L, Capitanio V, Bassi C, Di Carlo V and Pederzoli P: Parenchymapreserving resections for small nonfunctioning pancreatic endocrine tumors. Ann Surg Oncol 17(6): 1621-1627, 2010. PMID: 20162460. DOI: 10.1245/s10434-010-0949-8

65 Casadei R, Ricci C, Rega D, D'Ambra M, Pezzilli R, Tomassetti P, Campana D, Nori F and Minni F: Pancreatic endocrine tumors less than $4 \mathrm{~cm}$ in diameter: resect or enucleate? a single-center experience. Pancreas 39(6): 825-828, 2010. PMID: 20431423. DOI: $10.1097 / \mathrm{MPA} .0 \mathrm{~b} 013 \mathrm{e} 3181 \mathrm{cf} 155 \mathrm{c}$

66 Sallinen VJ, Le Large TYS, Tieftrunk E, Galeev S, Kovalenko Z, Haugvik SP, Antila A, Franklin O, Martinez-Moneo E, Robinson SM, Panzuto F, Regenet N, Muffatti F, Partelli S, Wiese D, Ruszniewski P, Dousset B, Edwin B, Bartsch DK, Sauvanet A, Falconi M, Ceyhan GO, Gaujoux S and Pancreas 2000 research group: Prognosis of sporadic resected small $(\leq 2 \mathrm{~cm})$ nonfunctional pancreatic neuroendocrine tumors - a multi-institutional study. HPB (Oxford) 20(3): 251-259, 2018. PMID: 28988702. DOI: 10.1016/j.hpb.2017.08.034

67 Cherif R, Gaujoux S, Couvelard A, Dokmak S, Vuillerme MP, Ruszniewski P, Belghiti J and Sauvanet A: Parenchyma-sparing resections for pancreatic neuroendocrine tumors. J Gastrointest Surg 16(11): 2045-2055, 2012. PMID: 22911124. DOI: 10.1007/s11605$012-2002-7$

68 Jilesen AP, van Eijck CH, in't Hof KH, van Dieren S, Gouma DJ and van Dijkum EJ: Postoperative complications, in-hospital mortality and 5-year survival after surgical resection for patients with a pancreatic neuroendocrine tumor: a systematic review. World J Surg 40(3): 729-748, 2016. PMID: 26661846. DOI: 10.1007/s00268-015-3328-6

69 Jilesen AP, van Eijck CH, Busch OR, van Gulik TM, Gouma DJ and van Dijkum EJ: Postoperative outcomes of enucleation and standard resections in patients with a pancreatic neuroendocrine tumor. World J Surg 40(3): 715-728, 2016. PMID: 26608956. DOI: $10.1007 / \mathrm{s} 00268-015-3341-9$

70 Zhang XF, Wu Z, Cloyd J, Lopez-Aguiar AG, Poultsides G, Makris E, Rocha F, Kanji Z, Weber S, Fisher A, Fields R, Krasnick BA, Idrees K, Smith PM, Cho C, Beems M, Schmidt CR, Dillhoff M, Maithel SK and Pawlik TM: Margin status and long-term prognosis of primary pancreatic neuroendocrine tumor after curative resection: Results from the US Neuroendocrine Tumor Study Group. Surgery 165(3): 548-556, 2019. PMID: 30278986. DOI: $10.1016 /$ j.surg.2018.08.015

71 Gratian L, Pura J, Dinan M, Roman S, Reed S and Sosa JA: Impact of extent of surgery on survival in patients with small 
nonfunctional pancreatic neuroendocrine tumors in the United States. Ann Surg Oncol 21(11): 3515-3521, 2014. PMID: 24841347. DOI: 10.1245/s10434-014-3769-4

72 Lo CY, Chan WF, Lo CM, Fan ST and Tam PK: Surgical treatment of pancreatic insulinomas in the era of laparoscopy. Surg Endosc 18(2): 297-302, 2004. PMID: 14712388. DOI: 10.1007/s00464-003-8156-3

73 Ayav A, Bresler L, Brunaud L, Boissel P, SFCL (Société Française de Chirurgie Laparoscopique). and AFCE (Association Francophone de Chirurgie Endocrinienne): Laparoscopic approach for solitary insulinoma: a multicentre study. Langenbecks Arch Surg 390(2): 134140, 2005. PMID: 15609056. DOI: 10.1007/s00423-004-0526-3

74 Sciuto A, Abete R, Reggio S, Pirozzi F, Settembre A and Corcione F: Laparoscopic spleen-preserving distal pancreatectomy for insulinoma: experience of a single center. Int J Surg 12(Suppl 1): S152-S155, 2014. PMID: 24862672. DOI: 10.1016/j.ijsu. 2014.05.023

75 Fernández-Cruz L, Martínez I, Cesar-Borges G, Astudillo E, Orduña D, Halperin I, Sesmilo G and Puig M: Laparoscopic surgery in patients with sporadic and multiple insulinomas associated with multiple endocrine neoplasia type 1. J Gastrointest Surg 9(3): 381388, 2005. PMID: 15749601. DOI: 10.1016/j.gassur.2004.06.009

76 Lopez CL, Albers MB, Bollmann C, Manoharan J, Waldmann J, Fendrich V and Bartsch DK: Minimally invasive versus open pancreatic surgery in patients with multiple endocrine neoplasia type 1. World J Surg 40(7): 1729-1736, 2016. PMID: 26956903. DOI: $10.1007 / \mathrm{s} 00268-016-3456-7$

77 Tamburrino D, Partelli S, Renzi C, Crippa S, Muffatti F, Perali C, Parisi A, Randolph J, Fusai GK, Cirocchi R and Falconi M: Systematic review and meta-analysis on laparoscopic pancreatic resections for neuroendocrine neoplasms (PNENs). Expert Rev Gastroenterol Hepatol 11(1): 65-73, 2017. PMID: 27781493. DOI: $10.1080 / 17474124.2017 .1253473$

78 Zhang XF, Lopez-Aguiar AG, Poultsides G, Makris E, Rocha F, Kanji Z, Weber S, Fields R, Krasnick BA, Idrees K, Smith PM, Cho C, Schmidt CR, Maithel SK, Pawlik TM and United States Neuroendocrine Tumor Study Group: Minimally invasive versus open distal pancreatectomy for pancreatic neuroendocrine tumors: An analysis from the U.S. neuroendocrine tumor study group. J Surg Oncol 120(2): 231-240, 2019. PMID: 31001868. DOI: $10.1002 /$ jso. 25481

79 Chin KM and Goh BKP: Robotic enucleation of a pancreatic uncinate neuroendocrine tumor - a unique parenchyma-saving strategy for uncinate tumors. Ann Hepatobiliary Pancreat Surg 24(1): 97-103, 2020. PMID: 32181437. DOI: 10.14701/ahbps. 2020.24.1.97

80 Takagi K and Koerkamp BG: Robotic total pancreatectomy: a novel pancreatic head-first approach (with video). J Gastrointest Surg 25(6): 1649-1650, 2021. PMID: 33570722. DOI: $10.1007 / \mathrm{s} 11605-021-04922-5$

81 Calin ML, Sadiq A, Arevalo G, Fuentes R, Flanders VL, Gupta N, Nasri B and Singh K: The first case report of robotic multivisceral resection for synchronous liver metastasis from pancreatic neuroendocrine tumor: a case report and literature review. J Laparoendosc Adv Surg Tech A 26(10): 816-824, 2016. PMID: 27454160. DOI: 10.1089/lap.2016.0342

82 Que FG, Nagorney DM, Batts KP, Linz LJ and Kvols LK: Hepatic resection for metastatic neuroendocrine carcinomas. Am J Surg 169(1): 36-42; discussion 42-3, 1995. PMID: 7817996. DOI: $10.1016 / \mathrm{s} 0002-9610(99) 80107-\mathrm{x}$
83 Sarmiento JM, Heywood G, Rubin J, Ilstrup DM, Nagorney DM and Que FG: Surgical treatment of neuroendocrine metastases to the liver: a plea for resection to increase survival. J Am Coll Surg 197(1): 29-37, 2003. PMID: 12831921. DOI: 10.1016/ S1072-7515(03)00230-8

84 Mayo SC, de Jong MC, Pulitano C, Clary BM, Reddy SK, Gamblin TC, Celinksi SA, Kooby DA, Staley CA, Stokes JB, Chu CK, Ferrero A, Schulick RD, Choti MA, Mentha G, Strub J, Bauer TW, Adams RB, Aldrighetti L, Capussotti L and Pawlik TM: Surgical management of hepatic neuroendocrine tumor metastasis: results from an international multi-institutional analysis. Ann Surg Oncol 17(12): 3129-3136, 2010. PMID: 20585879. DOI: $10.1245 / \mathrm{s} 10434-010-1154-5$

85 Morgan RE, Pommier SJ and Pommier RF: Expanded criteria for debulking of liver metastasis also apply to pancreatic neuroendocrine tumors. Surgery 163(1): 218-225, 2018. PMID: 29103583. DOI: 10.1016/j.surg.2017.05.030

86 Maxwell JE, Sherman SK, O’Dorisio TM, Bellizzi AM and Howe JR: Liver-directed surgery of neuroendocrine metastases: What is the optimal strategy? Surgery 159(1): 320-333, 2016. PMID: 26454679. DOI: 10.1016/j.surg.2015.05.040

87 Scott AT, Breheny PJ, Keck KJ, Bellizzi AM, Dillon JS, O'Dorisio TM and Howe JR: Effective cytoreduction can be achieved in patients with numerous neuroendocrine tumor liver metastases (NETLMs). Surgery 165(1): 166-175, 2019. PMID: 30343949. DOI: $10.1016 /$ j.surg.2018.04.070

88 Caplin ME, Pavel M, Ćwikła JB, Phan AT, Raderer M, Sedláčková E, Cadiot G, Wolin EM, Capdevila J, Wall L, Rindi G, Langley A, Martinez S, Blumberg J, Ruszniewski $\mathrm{P}$ and CLARINET Investigators: Lanreotide in metastatic enteropancreatic neuroendocrine tumors. N Engl J Med 371(3): 224-233, 2014. PMID: 25014687. DOI: 10.1056/NEJMoa1316158

89 Chauhan A, Horn M, Magee G, Hodges K, Evers M, Arnold S and Anthony L: Immune checkpoint inhibitors in neuroendocrine tumors: A single institution experience with review of literature. Oncotarget 9(10): 8801-8809, 2017. PMID: 29507655. DOI: 10.18632/oncotarget.23753

$90 \mathrm{Kim}$ J, Zimmerman MA and Hong JC: Liver transplantation in the treatment of unresectable hepatic metastasis from neuroendocrine tumors. J Gastrointest Oncol 11(3): 601-608, 2020. PMID: 32655939. DOI: 10.21037/jgo.2019.11.03

91 Moris D, Tsilimigras DI, Ntanasis-Stathopoulos I, Beal EW, Felekouras E, Vernadakis S, Fung JJ and Pawlik TM: Liver transplantation in patients with liver metastases from neuroendocrine tumors: A systematic review. Surgery 162(3): 525536, 2017. PMID: 28624178. DOI: 10.1016/j.surg.2017.05.006

92 Le Treut YP, Grégoire E, Klempnauer J, Belghiti J, Jouve E, Lerut J, Castaing D, Soubrane O, Boillot O, Mantion G, Homayounfar K, Bustamante M, Azoulay D, Wolf P, Krawczyk M, Pascher A, Suc B, Chiche L, de Urbina JO, Mejzlik V, Pascual M, Lodge JP, Gruttadauria S, Paye F, Pruvot FR, Thorban S, Foss A, Adam R and For ELITA: Liver transplantation for neuroendocrine tumors in Europe-results and trends in patient selection: a 213-case European liver transplant registry study. Ann Surg 257(5): 807-815, 2013. PMID: 23532105. DOI: 10.1097/SLA.0b013e31828ee17c

Received November 7, 2021

Revised November 25, 2021

Accepted December 1, 2021 